\title{
Aportes de Bartolomé de las Casas a la teoría actual de los derechos humanos*
}

JOSÉ WILMAR PINO MONTOYA**

Recibido: 27 de junio de 2019 . Evaluado: 6 de diciembre de 2019 - Aceptado: 9 de diciembre de 2019

Citar como: Pino Montoya, J. W. (2020). Aportes de Bartolomé de las Casas a la teoría actual de los derechos humanos. Hallazgos, 17(33), 221-253. DoI: https://doi.org/10.15332/2422409X.5240

* Artículo de reflexión resultado de la investigación "Productos de investigación: contextos en posconflicto”, aprobado y financiado por la Vicerrectoría de Investigaciones de la Universidad Católica Luis Amigó, Medellín, Colombia.

** Doctor en Filosofía y docente investigador de la Facultad de Educación y Humanidades de la Universidad Católica Luis Amigó, Medellín, Colombia.

Correo electrónico: jose.pinomo@amigo.edu.co

ORCID: https://orcid.org/0000-0001-9035-2058 


\section{Resumen}

La tesis principal de este trabajo es argumentar que los principios pensados por Bartolomé de las Casas, que le sirvieron para defender a los aborígenes de América de los actos de los españoles, parten del concepto filosófico de hombre y de los argumentos sustraídos, principalmente, de la tradición aristotélica, las teorías de Tomás de Aquino, los aportes de Francisco de Vitoria, del cristianismo y de su experiencia como clérigo y encomendero en las tierras americanas. De otro lado, se pretende sustentar que aún su pensamiento le aporta a la reflexión actual de los derechos humanos y a la construcción y consolidación de los Estados democráticos contemporáneos.

Palabras clave: aborigen, América, derechos fundamentales, hombre, ley natural.

\section{Contributions of Bartolomé de las Casas to the current theory of human rights}

\section{Abstract}

The main thesis of this work is to discuss that the principles thought by Bartolomé de las Casas, which served to defend the natives of America from the acts of the Spaniards, start from the philosophical concept of man and from the arguments drawn, mainly, from the Aristotelian tradition, the theories of Thomas Aquinas, the contributions of Francisco de Vitoria, Christianity and his experience as a cleric and encomendero in the American lands. On the other hand, it aims to support that his thinking still contributes to the current reflection of human rights and to the construction and consolidation of contemporary democratic states.

Keywords: native, America, fundamental rights, man, natural law.

\section{Aportes do Bartolomeu de las Casas à teoria atual dos diretos humanos}

\section{Resumo}

A tese principal deste trabalho é argumentar que os princípios pensados pelo Bartolomeu de las Casas, os quais serviram para defender aos aborígenes da América dos atos dos espanhóis, partem do conceito filosófico de homem e dos argumentos adotados, principalmente, da tradição aristotélica, as teorias do Tomás de Aquino, os aportes de Francisco de Vitoria, do cristianismo e de sua experiência como clérigo e encomendeiro nas terras americanas. Por outro lado, pretende-se sustentar que ainda seu pensamento aporta à reflexão atual dos direitos humanos e a construção e consolidação dos Estados democráticos contemporâneos.

Palavras-chave: aborígine, América, diretos fundamentais, homem, lei natural. 


\section{Introducción}

Papacchini (1995) habla sobre el concepto de los derechos humanos como "reivindicaciones de unos bienes primarios considerados de vital importancia para todo ser humano, que concretan en cada época histórica las demandas de la libertad y de dignidad” (p. 22). De otro lado, “[...] son aquellos que la persona posee de acuerdo a su naturaleza y los cuales adquiere solo por el hecho de haber nacido y compartir un espacio social" (Universidad Autónoma Latinoamericana y Corporación de Promoción Popular, 2001, p. 14). Para la adopción de este concepto en el momento actual, se ha de remitir, en primera instancia, a una perspectiva histórica, en la que en una etapa inicial "la conciencia de la dignidad humana, vale decir, lo que le corresponde a la persona para poder ser considerada como tal, emanaba de las religiones y la moral de cada grupo" (González y Bustamante 1997, p. 8).

En este tipo de sociedad, dicen González y Bustamante (1997), "los gobernados eran concebidos como súbditos, miembros de la sociedad carentes, pero no de deberes; el respeto de su dignidad era en última instancia una eventualidad derivada de la discrecionalidad de los gobernantes” (p. 8). Desde esta perspectiva, España, como primera potencia del mundo cristiano, conquista y coloniza a América, acontecimiento que trasciende y marca la historia de la fundamentación teórica y filosófica de derechos humanos, en tanto "[...] fue un tema obligado de reflexión para los teólogos españoles del siglo XVI, quienes reaccionaron elaborando una teoría teológicopolítica que reivindicaba los derechos de los nativos y limitaba severamente el poder de la corona" (Pino, 2003, p. 61) y, por consiguiente, el de los conquistadores en este territorio recién descubierto. "Ante este suceso, el movimiento lascasiano en favor del indio y en contra de dicha clase social, contribuyó a la cobranza del poder político" (Santamaría, 1982, p. 49), a través de diferentes mecanismos, entre estos las Leyes de Burgos, promulgadas en 1512, en las que el emperador Adriano propone una reforma, liderada por De las Casas, que consistía en la abolición del régimen de los repartimientos y Las Leyes Nuevas de Indias, las mismas que firmó el emperador Carlos $\mathrm{V}$ el 20 de noviembre de 1542, y con las que se mejoró notablemente la condición, el trato y la vida de los indios en las Américas, hasta tal punto que evitó su extinción total.

En este contexto, y por el aporte para el momento político y social actual, toman importancia las tesis planteadas por Bartolomé de las Casas y las reflexiones desarrolladas a la luz de los acontecimientos originados en el Nuevo Mundo, ya que "[...] hizo una apología de las culturas nativas en base a [sic] una vasta recopilación de material etnográfico” (Matos, 1990, p. 7). Además tuvo la influencia de las teorías elaboradas 
por la Escuela Española del Derecho Natural, cuya radicalidad democrática y lucha por la defensa de los valores inherentes a la dignidad humana sirvieron para sustentar y fundamentar la defensa de los nativos de América a partir de los derechos naturales, "porque todo derecho fundamental deriva su fuerza moral de la ley natural que lo contiene y que impone a los demás el correlativo deber" (Juan XXIII, 1963, p. 6).

Dentro de este marco, y dada la importancia adquirida por los derechos humanos en el presente siglo, la figura de De las Casas aparece imprescindiblemente como personaje unido a la actual problemática democrática y política de la sociedad moderna. Sus teorías, desarrolladas según el prisma de la filosofía jurídica y política del Medioevo, han rebasado en el transcurso de la historia los linderos de la reflexión teórica, y se han convertido en un valioso instrumento práctico para la democracia y la defensa de los derechos del hombre, hasta el punto de que ellos han sido el elemento inspirador de múltiples luchas y revoluciones que se han generado con el propósito de encontrar una mayor equidad e igualdad entre los hombres y las naciones.

En este sentido, se verá ahora la perenne actualidad de algunas de esas teorías nacidas del afán de fray Bartolomé de las Casas por defender a los indios y que hoy día han servido para construir la teoría moderna de los derechos humanos y justificar otras relacionadas con la democracia, la justicia y la política. "El trabajo filosófico que desarrolla Las Casas para fundamentar su defensa de los indios lo hace pertenecer a ese grupo de pensadores que [...] se ha preocupado por hacer uso de la filosofía para defender el derecho justo [...]” (Beuchot, 1991, p. 74).

Podríamos, de este modo, caracterizar las teorías de De las Casas como pertenecientes al campo de la filosofía, y en especial de la antropología filosófica y de la filosofía social. Campos a los que no se limitó, pues sus alcances fueron mucho más allá al desarrollar avances en la investigación empírica y fenomenológica que alimentaron, en el tiempo de la filosofía, sus postulados, que aunque fueron teorías de épocas pasadas, hoy conservan, como se anotará, una actualidad inalienable e innegable. Pero no podemos comenzar sin antes, por lo menos, mencionar cuáles son los cimientos en los que se basó Bartolomé de las Casas para tomar todas sus reflexiones.

\section{Concepción filosófica-antropológica del hombre}

Las reflexiones y las teorías desarrolladas por De las Casas fueron inspiradas por una visión antropológica del hombre, desligada no solo de una notable reflexión filosófica, 
sino también de las experiencias que le dieron los numerosos viajes que hizo a las Américas y de la cual tomó su propia perspectiva sobre aquellas gentes, al referirse a ellas de la siguiente manera:

Todas estas universas e infinitas gentes [1], a todo género crió Dios las más simples, sin maldades ni dobleces, obedientísimas, fidelísimas a sus señores naturales y a los cristianos a quienes sirven, más humildes, más pacientes, más pacíficas y quietas, sin rencillas ni bullicios, ni rijosos, ni querellosos, sin rencores, sin odios, sin desear venganza, que hay en el mundo virtuosos. (De las Casas, 1941, p. 4)

Esta visión del hombre americano tomada de la experiencia fue complementada con la tradición aristotélica, la misma que fue plasmada y distribuida a lo largo de toda la tradición literaria de Bartolomé de las Casas, quien entrelazó y plasmó de manera dispersa los aportes más significativos que le suministró Aristóteles sobre el tema: "Es perfectamente claro que el alma no es separable del cuerpo o, al menos, ciertas parte del alma pertenece a las partes misma del cuerpo” (Aristóteles II1, 1999[413a]). Tal reflexión filosófica le permitió comprender que los indios, al igual que los españoles, están dotados, si no de mejores, de iguales características y atribuciones que les permiten no solo gozar de los mismos derechos, sino también considerárselos dignos y dotados de razón como todos y cada uno de los hombres del resto del mundo.

Su lucha comienza a favor de los indios al considerarlos como hombre, y como tal es "un ser compuesto de dos elementos sustanciales distintos, un cuerpo material y un alma espiritual, que se funden en una unidad sustancial con un acto único de existencia, constituyendo un individuo perfecto, un yo, una persona" (Fraile y Urdanoz, 1985, p. 298). Partiendo de esta teoría y de su propia experiencia como colono

1 Esta visión del hombre americano y con la que Bartolomé defendía al indio del Nuevo Mundo fue contrapuesta a la concepción y a las características que insensiblemente le habían dado algunos hombres de su raza y su época, y la cual es retomada por Gonzalo Fernández de Oviedo (citado por Hanke, 1965), “quien consideraba a los indios (igual que a los hispanoamericanos ciertos peninsulares) como naturalmente vagos y viciosos, melancólicos, cobardes y en general gentes embusteras y holgazanas. Su ministerio no es un sacramento, sino un sacrilegio. Son idólatras, libidinosos y sodomitas. Su principal deseo es comer, beber, adorar ídolos paganos y cometer obscenidades bestiales. ¿Qué puede esperarse de una gente cuyos cráneos son tan gruesos y duros que los españoles tienen que tener cuidado con la lucha para no golpearlos en la cabeza, para que sus espadas no se emboten?” (p.15). 
y sacerdote con los indios de América, Bartolomé comienza a acumular y recolectar información para desarrollar su teoría sobre la justicia y los derechos, que luego fue interpretada e interpelada desde un enfoque eminentemente hermenéutico para tomar de allí los aportes realizados por las teorías contractuales de los Estados contemporáneos.

Siguiendo con esta misma perspectiva antropológica, De las Casas descubre que al ser el hombre un ser dotado, por naturaleza, de un cuerpo y un alma, es poseedor de ciertas características y cualidades que, siendo esenciales y propias, le imputan deberes y derechos. De lo que se deriva que el hombre sin distingo de raza, color o situación cumple unánimemente, y sin ser clasificado en niveles, la definición universal de ser un "animal racional”; por esto, y como todas las naciones del mundo son hombres, ninguna puede ser considerada con más privilegios que otra, o con mejores cualidades bajo el esquema de jerarquización, lo que lleva a concluir, como lo argumenta, Beuchot (1994) "que dada la naturaleza humana corporal-espiritual, se siguen ciertos atributos o predicados, unos esenciales y otros propios, que van a provocar deberes y derechos en el hombre” (p. 258).

Con este primer predicado que define al hombre como ser racional, el padre De las Casas pone al ser humano en un lugar distinto al de los demás seres de la naturaleza porque, como está dotado desde el principio de la razón, sus instintos y apetitos podrán ser de algún modo racionales. Esto quiere decir que en última instancia lo que sea elegido para subsanar los apetitos podrá ser escogido bajo el dominio de la libertad, que al ser guiada por la razón facilita la construcción de la vida social y libre.

De este primer predicado se desliga un segundo argumento: el de la libertad: "el hombre es libre", premisa que surge a partir de sostener que el ser humano ejerce su voluntad según los designios de la recta razón, mecanismo que es posible si se tiene en cuenta que para De las Casas la libertad nace precisamente de la interrelación que aparece cuando la razón ilumina y designa los destinos de la voluntad. De este modo, y acudiendo a las palabras de Beuchot (1994), "la existencia de una naturaleza humana garantiza la vigencia de un derecho natural, y, según este [nos dice De las Casas] hay libertad" (p. 35).

Seguidamente, y de este mismo argumento, surge para De las Casas la característica del hombre de vivir en sociedad o en compañía de otros, es decir, la capacidad de ser sociable, atributo que le permite al ser humano acceder con mayor capacidad a los satisfactores que necesita para suplir sus necesidades o carencias individuales, porque solo en compañía de los demás tiene el hombre lo necesario para la vida humana. 
Es, no obstante, en la especie animal humana, donde esta complejidad es más marcada, puesto que la cooperación entre la mujer y el hombre tiende no solamente a la existencia, sino a una existencia feliz [...]

Al mismo tiempo, la naturaleza, con sus ciclos de cambios, sigue su cometido de perpetuar la existencia, preservando el tipo, cuando ella es inepta para preservar el individuo. Así, con esta intención por delante, la divina providencia ha modelado la naturaleza del hombre y la mujer para su asociación y convivencia. (Aristóteles I3, 1994 [1343b])

De todos estos predicados esbozados, y tomados en su conjunto, se desprende finalmente la religiosidad que según De las Casas es la característica o el don que lleva al hombre a inclinarse y a buscar la religión, en la medida en que es una búsqueda constante de la verdad y el bien iluminado por la razón. Así, la religiosidad es la búsqueda de la máxima verdad y del bien supremo que, en última instancia, es la búsqueda incansable de Dios, y no solo es percibido o captado con el mero instrumento de la racionalidad natural, sino que tal racionalidad debe estar acompañada de la revelación. De esta combinación nace el derecho del hombre a tener acceso a la verdadera y única fe. Refiriéndose a lo anterior, De las Casas (1975) argumenta:

[...] el modo de enseñarle a los hombres la verdadera religión debe ser delicado, dulce y suave. Pero este modo no es otra cosa sino la persuasión del entendimiento y la moción de la voluntad, como se probará adelante. Luego la provincia divina ha establecido, para todo el mundo y para todos los tiempos, un mismo y solo modo de enseñarles a los hombres la verdadera religión, a saber, la persuasión del entendimiento y la invitación o excitación de la voluntad. (p. 67)

En otra parte, De las Casas (citado por Hanke, 1949) afirma:

El modo de enseñar, de encaminar o de traer al seno de la fe y de la religión cristiana a los hombres que se encuentran fuera de él, debe ser un modo que persuada al entendimiento y que mueva, exhorte o atraiga suavemente la voluntad. (p. 29)

Hasta aquí quedan planteados los principales aportes que realizó Bartolomé de las Casas a las concepciones actuales del hombre, sustraídos del concepto aristotélico-tomista del ser humano y de las reflexiones y consideraciones desarrolladas de su experiencia en las Indias. No obstante, esta no es la única fuente de la cual bebió el zumo. De las Casas, para darle base teórica a sus reflexiones y hacer su defensa de los indios, además fue influenciado por la Escuela Española del Derecho Natural, por 
Francisco de Vitoria y la teoría del iuscomunicationis y por la discusión que sostuvo con Juan Ginés de Sepúlveda y su teoría paternalista.

\section{La Escuela Española del Derecho Natural}

Alrededor de nuestra primera reflexión se dirá que los fundamentos filosóficos más relevantes elaborados por los iusnaturalistas clásicos españoles, compuesta principalmente por Vitoria, de Soto, Molina y Vásquez, quienes retomaron los aportes teóricos de Tomás de Aquino plasmados en su Suma teológica ${ }^{2}$ y aprovechando la coyuntura política de la conquista de América, quisieron poner en práctica aquellas doctrinas para, de este modo, asegurar la supremacía en toda Europa de la moral cristiana. En este sentido, los Clásicos Españoles del Derecho Natural ${ }^{3}$ lograron desarrollar algunos temas de orden jurídico político con miras a defender a los indios del Nuevo Mundo. De estos temas solo nos interesa resaltar el relacionado con las libertades, ya que fue esta perspectiva la que sirvió a De las Casas para sostener sus premisas.

En la postura jurídica sobre las libertades, los clásicos españoles son indudablemente iusnaturalistas, ya que entendieron el iusnaturalismo como:

La teoría que afirma la existencia y la posibilidad de conocimiento del derecho natural, el cual, y como ya se ha dicho, es entendido generalmente como un conjunto de normas y/o principios emanados de la naturaleza, que son anteriores y superiores al derecho positivo, es decir, al derecho nuestro o impuesto por el poder político. (Pérez-Luño, 1998, p. 510)

2 "En lo referido al pensamiento medieval, es fundamental Santo Tomás de Aquino con su distinción entre ley eterna, ley natural y ley positiva. Entiende por ley eterna la 'razón de la divina sabiduría'; concibe la ley natural como la participación en la ley eterna, en virtud de la cual el hombre puede distinguir entre el bien y el mal. En este sentido, Santo Tomás es uno de los más grandes representantes de la concepción iusnaturalista — de aquí se deduce que—, en cuanto al iusnaturalismo escolástico, es central la figura de Santo Tomás y su afirmación de la racionalidad de la ley: en efecto, entiende la ley como 'el ordenamiento de la razón en busca del bien común, promulgado por la autoridad pública'. Este concepto está muy ligado a la idea medieval de Ordo, entendido como la forma de existir de todo lo creado como fruto de la inteligencia divina" (Pérez-Luño, 1998, p. 510).

3 'Esta denominación enlaza con la de 'magni Hispani', que fue utilizado por Joseph Kohler para aludir a la más valiosa y persistente herencia intelectual de los principales tratadistas hispanos del derecho natural" (Pérez-Luño, 1998, p. 510). 
Al considerar la idea de naturaleza, los Clásicos Españoles del Derecho Natural la entendieron, según Pérez-Luño (1998), desde tres puntos de vista diferentes. La primera es la concepción de naturaleza como cosmos, o, de otro modo, son aquellas leyes que rigen y guían el mundo; mundo del cual forman parte también los hombres que se hallan sujetos a su legalidad a través de los instintos y de sus necesidades naturales. La segunda es la idea de naturaleza creada por Dios, es decir, como creación divina; de allí que el derecho natural sea tomado o interpretado como una expresión reveladora de la voluntad del creador en el ámbito de las relaciones sociales. La tercera y última concepción de naturaleza es aquella que la interpreta como naturaleza dotada de razón, que es la cualidad especifica del ser humano, que le permite autónomamente establecer las normas básicas de convivencia, ya que la razón es la esencia misma del hombre que le permite fundamentar y legitimar el derecho y la política. Además, su explicación iusnaturalista es el principal mérito de la historia del derecho natural porque a través de los tiempos ha cumplido la tarea de educar a la humanidad para organizar racionalmente, esto es, humanamente, la convivencia, por cuanto esta tiene sus bases, no en el capricho o arbitrio del hombre, sino en la misma razón.

Desde la reflexión iusnaturalista, los Clásicos Españoles “profesaron un decidido cognitismo al defender la capacidad dela razón práctica para acceder a un orden ético objetivamente válido que debía inspirar la convivencia humana” (Pérez-Luño, 1998, p. 513). En este orden de ideas, lo que pretendían era proponer un objetivismo ontológico del que se derivan una serie de valores y principios materiales universalmente válidos ${ }^{4}$. Un primer principio fue el bien común, que es precisamente una categoría vinculada a una concepción escatológica de la persona y del orden político, y que para los Clásicos Españoles tiene una importante operatividad terrenal, en la medida en que establece un límite al ejercicio del poder político, fundamenta la resistencia frente a la opresión y explica la convivencia social en términos de solidaridad. Como segundo principio sobresale la teoría de las libertades. En lo que respecta a esta teoría, la Escuela Española del Derecho Natural descolló principalmente en la exposición y argumentación de las libertades desde el punto de vista práctico, sobrepasando las iniciativas de Tomás de Aquino, quien estructuró sus argumentaciones desde una perspectiva especulativa dirigida solo al conocimiento teórico.

4 "Esta pretensión - la de derivar una serie de valores y principios materiales universalmente válidos- contraría con el pluralismo, el historialismo o el consenso intersubjetivo que hoy se consideran pautas de referencia obligada en la axiología contemporánea" (Pérez-Luño, 1998, p. 513). 
Así, los aportes que más se le reconocen al iusnaturalismo clásico español se pueden resumir en tres puntos, a saber: la actitud metódica procedimental; la formación del contractualismo moderno; un continuo ejercicio de la teoría de la "racionalidad discursiva", representada a lo largo de todas sus obras.

Con lo anterior se demuestra la importancia de las reflexiones sobre la filosofía práctica que hizo la Escuela Española del Derecho Natural $^{5}$, y cuáles fueron sus aportes más significativos para la construcción actual de un sistema de leyes que mantenga el orden y la igualdad entre los hombres. Sobre la importancia de la Escuela Clásica del Derecho Natural, Wiacker (citado por Carrión, 1991) dice: "Estos pensadores españoles, pertenecientes al florecimiento cultural del Siglo de Oro español, han sido estimados desde algún tiempo como los reales precursores del moderno derecho racionalista” (p. 102).

\section{La Universidad de Salamanca}

La influencia, aunque de manera indirecta, de la Universidad de Salamanca en la vida y obra de Bartolomé de las Casas se da porque el claustro universitario, para la época, era escenario de grandes e importantes debates de carácter jurídico, ético y político. Esto, unido al papel que cumplió como unidad académica y de opinión

5 "Como reflejo del pensamiento de Santo Tomás, es especialmente relevante la denominada Escuela Española del Derecho Natural que presenta aportes muy importantes en lo referido a la teología moral en los siglos xVI y xviI. En efecto, dicha escuela tiene el mérito de haber abordado, de modo original y novedoso, muchas cuestiones de carácter jurídico y moral que hasta entonces no habían sido tratados en las universidades [...]. Como características comunes de las representantes de dicha escuela pueden señalarse las ideas del origen divino del derecho natural —de acuerdo con la doctrina Tomista de la participación_-, de la coexistencia del derecho natural con el derecho positivo y de la vigencia y obligación del derecho natural; ya que los hombres no pueden ignorarlo en cuanto a sus principios universales” (De la Puente, 1999, p. 19).

Como complemento a los anteriores argumentos y retomando a Osuna Fernández, De la Puente (1999) agrega: "el objetivo fundamental de dicha escuela fue teorizar sobre "la necesidad del derecho en la vida social y su puesto en el plan salvador de Dios. Más específicamente, el derecho natural que ellos proponían era ante todo los principios ineludibles de un orden justo. Aquellos autores eran conscientes de la dimensión práctica de su saber, al poner sobre el tapete problemas de orden político, tales como la obediencia a las leyes injustas, el uso de la equidad por los jueces, o la mutabilidad de las leyes naturales y hasta la legitimidad del tiranicidio y de la rebelión contra la autoridad" (p. 20). 
pública frente a los acontecimientos sucedidos en la época en España, en relación con la conquista del Nuevo Mundo y el trato que dieron estos a los autóctonos americanos, formó los excelsos y célebres intelectuales de la época, de los que Bartolomé retomó su forma propia de exponer y elaborar sus pensamientos. A estos estudiosos, según las palabras De Dios de Dios (2006), se les reconoce en la historia como humanistas.

Caracterizados por su cultura, su buen latín, su gusto por las antigüedades y sus ansias de reconstrucción filológica e histórica de los textos romanos y canónicos también se preocuparon por el método, por la brevedad y sencillez, y por la originalidad, cuestionando la communis opinio y el masivo recurso a las citas de autoridad, así como fue notorio en algunos su interés por las cuestiones teóricas, comenzando por la definición, especies y reglas de derecho y siguiendo por la apelación a la razón natural. (p. 82)

Con estos argumentos sobre los alcances propios de los académicos de la Universidad de Salamanca, se le reconoce a esta institución la manera particular de difundir y practicar su pensamiento, sus reglas de apropiación teórica y su forma de impartir el conocimiento; además cultivaban e integraban de forma paralela, y sin confundir, las concepciones teológicas, filosóficas y de jurisprudencia. Estas creencias se reflexionaban a la luz de cuatro teorías: las tendencias de la filosofía clásica, retomando principalmente los postulados y los alcances teóricos de Platón, Aristóteles y Cicerón; la tradición escolástica, en la que se toma como fuente primordial a Tomás de Aquino, con su Suma teológica; beben del zumo humanista, evidenciándose así en muchos las teorías y las reflexiones que al respecto hizo Erasmo; y retoman los principales argumentos de la tradición romanojustiniana y canónicas del ius communune, a lo que se le suma todo aquel acervo jurídico hispánico de los siglos XV y XVI.

En su generalidad, la Universidad de Salamanca es relevante en la construcción teórica y práctica de sus maestros y alumnos, porque dio y construyó en ellos trascendentales fundamentos conceptuales y prácticos relacionados con lo teológico, lo jurídico y lo humanista. Estos fijaron durante siglos una metodología, una temática y una capacidad crítica frente a los hechos que sirvieron para que se levantaran en defensa de los derechos del hombre y de los pueblos autóctonos del Nuevo Mundo. 


\section{Francisco de Vitoria y la teoría del iuscomunicationis}

Los aportes de Francisco de Vitoria ${ }^{6}$ a la teoría de los derechos humanos en Bartolomé de las Casas también fueron sustentados a partir de la idea del derecho natural.

El derecho natural es el conjunto de comportamientos que son justos en función de las exigencias del comportamiento humano universal y que viene expresado por la luz de la razón humana, antes de cualquier toma de posición por cualquier legislación y en cualquier situación concreta de las relaciones sociales. (De la Puente, 1999, p. 17)

Dentro de este marco, Francisco de Vitoria, como iusnaturalista clásico español, trató de ofrecer un diagnóstico y de responder a los retos de su época mediante el escrito La relectro de Indias, que fue leído por él mismo en la Universidad de Salamanca en 1539, y que se convirtió en una de las primeras y más importantes muestras para su propósito. La idea principal plasmada en sus lecciones se basa en la creencia y en la expresión de la existencia de un decidido humanismo cosmopolita, una comunidad de todos los hombres y los pueblos de la tierra, cuyo principal sustento era el derecho de gentes, sustentado en el derecho natural, que sirve como fundamento para reconocer plena personalidad jurídico-internacional a todos los pueblos, incluidos los no cristianos.

Con esto Vitoria pretendía abogar por un derecho común de la humanidad, cuyos principios alcancen la validez universal y cuyos postulados tenían sus más profundas raíces en la unidad del género humano y su corolario, que se sustenta en la igualdad y libertad de todos los hombres y pueblos. Vitoria reformulaba desde allí, y ahora desde la perspectiva humanista renacentista de su tiempo, los mismos ideales

6 Aunque a Vitoria se le ha considerado como un personaje contradictorio porque sus teorías ayudaron y sirvieron para justificar la conquista de América, es necesario aclarar que su sensibilidad hacia los indios era irrefutable. Esta la hace saber y quizás se precisa en la siguiente nota: "Francisco de Vitoria considera que a los aborígenes no se les debe privar de derechos y propiedades puesto que no son bárbaros ni esclavos naturales; tampoco el Papa puede dar autoridad sobre los infieles a los príncipes cristianos, ni aún en castigo por pecados contra la naturaleza [...] Para Vitoria, la unidad del género humano no se lograba por la acción conjunta de poderes universales sino por los principios racionales de una ley natural, que regulaba la coexistencia de los diferentes Estados nacionales por medio de la referencia al derecho internacional: la res pública se subordinaba al ius gentium" (Salazar, 2000, p. 7). 
definidos por la estirpe estoico-ciceroniana, que fueron prolongados luego en el iusnaturalismo racionalista medieval. Se refiere a este argumento cuando afirma:

A su vez la voluntad, cuyos ornamentos son la justicia y la amistad, quedarían del todo deformes y defectuosas, alejadas del consorcio humano; la justicia, en efecto, no puede ser ejercitada sino entre la multitud, y la amistad, sin la cual no disfrutamos del agua ni del juego ni del sol, como Cicerón dice en muchos lugares [...]. (Vitoria, 1974, pp. 5-6)

Este fue el mismo argumento que utilizó para justificar la presencia de los españoles en América, diciendo que lo único que pretendía la conquista era la sociabilidad y la comunicabilidad humana. Porque la facultad de cambiar ideas y experiencias mediante el lenguaje es un atributo definitorio del género humano. Agrega Vitoria (citado por Pérez-Luño, 1998): "Sin comunicación no puede existir conocimiento entre los hombres, tampoco relaciones mutuas basadas en la cooperación; en suma, sin ella no es posible la sociedad o comunidad" (p. 538). De este modo, entonces, la comunidad de los hombres y la comunidad del orbe tienen como presupuesto la comunicación, que es una comunicación a la naturaleza. En palabras de Hanke (citado por Novak y Ruda, 1999):

La piedra angular del sistema de Vitoria que algunos juristas consideran hoy como la verdadera base del derecho internacional, era la igualdad de los Estados, aplicable no solo a los de la cristiandad y de Europa, sino también a los principados bárbaros de América. (p. 25)

\section{Bartolomé de las Casas y su disputa con Juan Ginés de Sepúlveda}

Sepúlveda defendió la conquista y la invasión que realizó España a las Indias. Los argumentos con los cuales defendió tal acontecimiento se podrían resumir en las siguientes dos conclusiones:

La una es que las guerras que se han hecho por los españoles contra los indios fueron justas de parte de la causa y del auctoridad que hay para movellas, y que lo mismo se pueden y deben, generalmente, contra ellos hacer. La otra es que los indios son obligados a se sometan para ser regidos por los españoles, como menos 
entendidos, a los más prudentes, y si no quieren, afirma que les pueden hacer guerra. (De las Casas, 1985[1552], p. 165)

Estas dos conclusiones fueron sustentadas en cuatro razones. La primera, por la idolatría, que, según el defensor de la Conquista, cometían los pobladores de las Indias, y por otros pecados que iban en contra de la ley natural. La segunda es que, por la rudeza de sus ingenios, por ser de naturaleza servil y por ser bárbaros, estas gentes deben ser obligadas a servir a los ingenios más elegantes, como los españoles. Como tercera razón se argumenta que es por el fin de la fe, porque mediante este medio de guerra es más fácil su predicación. Por último, se argumenta que es por el daño que se hacen entre sí, matando hombres, y en algunos casos por comérselos. El siguiente pasaje de la discusión entre Sepúlveda y De las Casas (1996) sustenta lo anterior:

[...] con perfecto derecho los españoles imperan sobre estos bárbaros del Nuevo Mundo é islas adyacentes, los cuales en prudencia, ingenio, virtud y humanidad son tan inferiores a los españoles como los niños a los adultos y las mujeres a los varones, habiendo entre ellos tanta diferencia como la que va de gentes fieras y crueles á gentes clementísimas, de los prodigiosamente intemperantes á los continentes y templados, y estoy por decir que de monos á hombres. (p. 101)

Por su parte, De las Casas aprovechó aquel encuentro para exponer sus teorías en favor de los indios, utilizando los argumentos que construyó a partir de la lectura de las obras de Aristóteles y de Tomás de Aquino, que, unidos a su experiencia en las Indias, le suministraron el conocimiento y el coraje necesario para cimentar su capacidad reflexiva, demostración teórica y sensibilidad humanista para denunciar los peligros y los daños que contenían las teorías de Sepúlveda.

La apología y los argumentos que expuso Bartolomé en favor de los indios se resumen en los puntos y argumentos que se presentan a continuación. En primer término, y para dar respuesta a la primera de las razones sustentadas por Sepúlveda, dice De las Casas que estas guerras contra los gentiles idólatras no las mandó Dios a todos los pobladores de las naciones por ser idólatras, sino que las envío en particular, y en su respectiva época, contra los cananeos y jebuseos, y a siete naciones a las que hace mención en el Deuteronomio, que poseían la tierra de promisión, es decir, la tierra prometida a Abraham y su linaje. De igual modo, porque se allega contra esta razón lo que dice san Lucas en el capítulo 14. Allí argumenta que es entendible una intromisión de un estado exterior a otro mediante la guerra en los siguientes dos sentidos: si todo el linaje está en pecado y, particularmente, si todos sus gentiles nunca oyeron la fe. Un tercer argumento es que es falso que algunos emperadores, 
por consejo de algunos santos, hicieron la guerra a varios pueblos con el fin de quitarles la idolatría y traerlos a la fe, y, para ello, mostró que esto fue falso en tiempos de Constantino y en tiempos de san Silvestre. El cuarto punto con el que prueba Bartolomé que los indios americanos no pueden ser castigados por idolatría es porque dicho castigo no pertenece a la Iglesia, sino al mismo Dios. "De suerte que por estos cuatro puntos respondió a la primera probación del doctor Sepúlveda, donde por auctoridad y ejemplo de las sagradas escrituras quería probar que por razón de la idolatría se les puede hacer guerra a los gentiles” (De las Casas, 1985, p. 182).

En respuesta a la razón segunda argumentada por Sepúlveda, y en la cual afirma que "por la rudeza de sus ingenios, que son de su natural gente servil y bárbara, y por ende obligadas a servir a los ingenios más elegantes como son los españoles" (De las Casas, 1985, p. 171), y en la que se funda la barbarie de aquellas gentes, De las Casas replica que existen tres clases de bárbaros, y que, por lo tanto, y para declarar la guerra a los aborígenes por este término, ha de precisarse, muy bien, su clase de barbarie. En primer término, dice el defensor de los indios, la palabra bárbaro ha de entenderse para designar a aquellas gentes que tienen alguna extrañeza en sus opiniones o costumbres, pero no les falta policía ni prudencia para regirse. De las Casas se refiere a otras clases de culturas que por su costumbre y manera de ver el mundo no son iguales a otras, en este caso a la española, que es la que ejerce su poder y su hegemonía, y por ello, por sus diferentes costumbres, se les hacen extrañas y poco conocidas otras culturas; no obstante, tienen formas de organizarse y mantener la paz entre sus miembros. La segunda clase de bárbaros es aquella que no ha desarrollado un lenguaje claro y apto para comunicarse, ni entre ellas ni con las demás poblaciones; es decir, no han desarrollado un sistema de signos y códigos comunes que facilite su comunicación con otras culturas y consigo mismas. En otras palabras, son poblaciones que aún no han desarrollado un idioma. Como ejemplo pone a los ingleses. Como última y tercera clase de bárbaros, trae a propósito aquellas especies de

[...] perversas costumbres y rudeza de ingenio y brutal inclinación son como fieras silvestres que viven por los campos, sin ciudades ni casas, sin policía, sin leyes, sin ritos ni tractos que son de iure gentium, sino que andan palantes, como se dice en latín, que quiere decir robando y haciendo fuerza. (De las Casas, 1985, p. 171)

Son a estos últimos, y según lo expuesto por Aristóteles, a los que se les debe cazar como a fieras, a los que se es lícito hacer la guerra, todo porque son ellos los que pueden hacer daño, y a los que hay que poner bajo la custodia, el cuidado y la fuerza de la ley humana. 
Con la explicación de estas tres especies de bárbaros, De las Casas define la naturaleza de los indios americanos, pues si fueran los indios de América esta última clase de bárbaros, sería y haría legítima su evangelización por medio de la guerra y la violencia. Con relación a este punto, en el que se defiende al aborigen americano como no partícipe de esta clase de bárbaro, dice De las Casas (1985):

Por esta ocasión el señor obispo contó largamente la historia de los indios mostrando que, aunque tengan algunas costumbres de gente no tan política, pero que no son en este grado bárbaros, antes son gente gregátil y civil, que tiene pueblos grandes y casas y leyes y artes y señores y gobernación, y castigan no solo los pecados contra natura, más aún otros naturales con penas de muerte. Tienen bastante policía para que por esta razón de barbaridad no se les pueda hacer guerra. (p. 95)

Sustentado en este argumento, De las Casas pide evangelizar y atraer a los indios americanos con mecanismos y actitudes de paz, armonía y amor.

Pasando ahora a lo dicho por el fraile para irse en contra del tercer argumento expuesto por Sepúlveda para practicar o declarar lícitas las guerras en las Indias, trae a propósito seis razones por la cuales la Iglesia puede declarar la guerra a las poblaciones, y por supuesto no era el caso de los indios americanos. Entonces, según De las Casas, la Iglesia puede hacer la guerra a las poblaciones si estas tienen ocupadas violentamente las tierras que antes fueron de cristianos; si con pecado grave de idolatría ensucian y contaminan nuestra fe, sacramentos, templos o imágenes; si blasfemasen el nombre de Jesucristo, de los santos o de la Iglesia; si impiden la predicación de la fe, conociendo lo que impiden; si ellos les hacen o declaran la guerra; y por último, y como sexta razón, se argumenta que a la Iglesia le es encomendada, por ley natural y para librar a los inocentes, su custodia, su cuidado y su protección.

Pero estos no fueron los únicos argumentos con los cuales Bartolomé defendió la raza indígena de la tercera razón expuesta por Sepúlveda para declarar la guerra a América. El defensor de los indios se valió de dos argumentos. El primero es que la fe no se puede demostrar de acuerdo con la capacidad natural o con una capacidad innata; esta ha de integrar el entendimiento y una pía afición en los que han de predicarla e introducirla para que con el ejemplo de sus vidas sean testimonio de un verdadero Dios, a quien se le predique y para que más fácil la crean. Por ello son contrarias las guerras que preceden a la predicación. El segundo se refiere a que, en la predicación de la fe, también se incluye la predicación de la penitencia, es decir, la predicación de la fe debe incluir el perdón de los pecados pasados sin castigo 
ninguno, y esto ha de hacerse de manera universal con todas las gentes, incluidos, entre ellas, los indios. Al respecto dice Bartolomé: "luego, aunque ellos [refiriéndose a los indios americanos] mereciesen pena por ello, no se les ha de castigar y hacer guerra, sino predicarles que todo se les ha de perdonar por el baptismo" (De las Casas, 1985, p. 189).

La respuesta que da Bartolomé de las Casas a la cuarta razón dada por Sepúlveda para practicar la guerra contra los indios se funda en cuatro argumentos. En primer lugar, arguye que de dos males es mejor elegir el menor, y que en caso de que los indios maten algunos inocentes para comerlos, que es aún mayor fealdad que sacrificarlos, es sin lugar a dudas menor mal que los males que se siguen de las guerras y de los abusos que practican los españoles. En segundo lugar, se tiene el mandamiento "no matarás", en especial al inocente y al libre de culpa. El tercer argumento es que los indios americanos tienen excusa para no ser obligados a aceptar la fe cristiana, y menos aceptarla de personas armadas, que en vez de presentarse como amigos son enemigos que solo van a matar y robar. Los indios, según los argumentos del padre De las Casas, tienen, pues, la excusa de no saber aún sobre la fe cristiana hasta cuando no se les obligue a creer o la acepten por voluntad propia; por ello no tienen culpa ni tampoco merecen ser castigados. En este mismo orden, no son obligados a entender porque, y por naturaleza, algunos pueblos conciben su propio dios, al que consideran como cosa excelentísima y a quien todos hacen reverencia con el sacrifico de las mejores cosas que tienen los hombres. Por eso es que en su ignorancia y excusa ofrecen sus vidas y las de algunos niños inocentes y sin culpa para recibir beneficios. Por último, dice De las Casas, no se les debe hacer guerra a los aborígenes americanos porque muy fácilmente, y a través de la razón, se les puede convencer para dejar la idolatría y convertirse a la fe cristiana.

El padre Bartolomé de las Casas defendía lo contrario a Sepúlveda, utilizando una incomparable capacidad de deliberación, sustentación teórica y sensibilidad humana, para afirmar que era injusta la guerra y la violencia que se estaba usando como medio para evangelizar y predicar la palabra de Dios en el territorio descubierto por los españoles, ya que esta tarea debía realizarse de modo pacífico.

[...] A todos los herejes y mucho más a los que nunca recibieron la fe ni ofendieron a la iglesia, se ha de ofrecer primero paz, declarando y dándoles noticia y conocimiento del mesmo Cristo, hijo de Dios que es la verdad. Y la pelea contra ellos ha de ser con los testimonios de la Escritura; el herirlos, con el cuchillo del Evangelio en la predicación benigna, dulce, con mansedumbre y con humildad. (De las Casas, 1985, p. 223) 
Según Pérez-Luño (1998), y con las réplicas dadas a las tesis de Sepúlveda, Bartolomé de las Casas se anticipó en siglos a la penetrante crítica kantiana, del paternalismo político, ya que, en contra de las teorías expuestas por el cronista del emperador, ante la Junta de Valladolid, expone:

Todas las naciones del mundo son hombres y de cada uno de ellos es una norma, la definición, y ésta es que son racionales, esta racionalidad es la fuente de la libertad de todos los hombres y los pueblos, e impide cualquier forma de paternalismo en cuanto intervención ajena en sus asuntos, sin su consentimiento [...] porque la elección de los reyes y de quien hubiere de regir los hombres y los pueblos libres, pertenece a los mismos que han de ser regidos, de ley natural y Derecho de las gentes, sometiéndose ellos mismos al elegido por su propio consentimiento, que es acto de la voluntad que en ninguna manera puede ser [...] forzada como quiera que los hombres todos al principio naciesen y fuesen libres. (Pérez-Luño, 1998, p. 527)

A partir de estos argumentos, las reflexiones que expuso en su controversia con Sepúlveda, y en sus importantes reflexiones tomadas por su experiencia y práctica realizada con los indios americanos, De las Casas inició su trascedente aporte a las teorías de los derechos del hombre en lo que respecta principalmente, y en primera instancia, a la defensa del derecho a la vida, en lo que concierne a la libertad de conciencia y al derecho privado y público.

Con tales premisas, De las Casas comenzó su gran aporte al sistema jurídico y a la teoría de los derechos fundamentales, a través de sus importantes reflexiones prácticas en el plano de la libertad de conciencia, el derecho privado y el derecho público, como lo veremos a continuación.

\section{Teoría de los derechos humanos y tesis democrática}

Ligada entonces a la problemática ético-jurídica que aparece con la conquista de América y a las reflexiones teóricas elaboradas por la Escuela Española del Derecho Natural, sobresale la figura de fray Bartolomé de las Casas. Él, desde el prisma de la filosofía jurídica y política, rebasa los linderos estrictamente doctrinales de la elaboración teórica, por la propia amplitud de sus inquietudes y objetivos, y porque no solo se aventura a conjeturar con sus reflexiones sobre el derecho y los problemas políticos sobre su época, y más precisamente sobre la situación de los indígenas de América, 
sino también porque sus teorías tuvieron un sentido práctico, instrumental y subordinado a un objetivo preciso: defender y librar una lucha incansable en favor de los nativos. Esto, sin lugar a duda, lo convierte en un valioso exponente de las doctrinas iusnaturalistas de corriente democrática, a cuyo desarrollo contribuyó poderosamente, puesto que dejó, con sus notables reflexiones, una importante aportación al devenir histórico de los derechos humanos.

Dentro de este contexto y sustentado en la siguiente premisa: "La raíz del problema está en que una cosa así es muy grave y extremadamente funesta para los pueblos. Y, sin embargo, vemos que se repite a cada paso dentro de los reinos y sin el menor escrúpulo", el padre De las Casas propone su teoría sobre los derechos humanos basado en el derecho natural, derechos con los que buscaba defender la dignidad y la conservación de la vida de los aborígenes del Nuevo Mundo.

Por esta razón, y en lo que sigue, se presenta la manera como el defensor de los indios fundamenta los principales derechos humanos en los derechos naturales, y que al ponerlos en práctica buscan como fin último la justicia en América, que se podría considerar una característica que debe tener la sociedad y que nace también de la propia naturaleza humana. Al respecto, y refiriéndose a la justicia y al derecho en De las Casas, anota Beuchot (1986):

Es algo que se da en todos los seres humanos, sin distinción de grados o jerarquías [...] tiene que pertenecerles sin distinción ni jerarquías sino con equidad, ya que no es sino el derecho que se desprende de la naturaleza humana, que es igual en todos y común a todos ellos por igual [...] Y la naturaleza humana es la razón, la racionalidad, por ello pertenecerá al derecho natural aquello que surge de la naturaleza racional del hombre, lo que es conforme a la razón... Esta ley natural o derecho natural es intocable, ninguna autoridad está por encima de ella ni puede derogarla [...] Y por ningún pecado, por nefando que sea, se priva al hombre de los viene naturales ni del derecho natural. (p. 259)

Esta abstracción de la justicia y la equidad, sustraída por De las Casas de las teorías aristotélicas para sustentar la defensa de los indios, es la que posteriormente se convertirá en argumentos válidos para conformar lo que podría llamarse una "sociedad bien ordenada". Una sociedad fundamentada en algunos principios que tengan como fin dar a los individuos de una nación los satisfactores necesarios a sus carencias, pero de forma equitativa y equilibrada, sin ningún tipo de privilegios y exclusiones. Este sería el mecanismo más justo y adecuado para encontrar el bien colectivo a partir de considerar a las personas en igualdad de condiciones: racionales, 
justos y libres. Esta es la condición primordial para la construcción social de un orden que deje por fuera la promoción de los intereses individuales y particulares de los hombres, que, como bien se entiende, es la principal causa de las injusticias.

A partir de estas consideraciones resulta fácil inferir que las Casas aparece como un mito y una bandera de los derechos y de la dignidad, para asíllegar a la conclusión de que: toda su obra es un grito de libertad y liberación, desde el derecho natural y la fuerza del evangelio. (Pérez-Luño, 1998, p. 553)

Con lo anterior, el padre De las Casas deja plantadas las bases esenciales para que las sociedades modernas busquen, a través de la aplicación de la justicia y los derechos humanos, un orden social más equitativo, digno y justo para todos los hombres. Estos argumentos hoy en día son utilizados para que en todo grupo humano y en toda nación firmen y construyan normas de convivencia, de justicia, de conducta recta y, en conclusión, de una elaboración social que tenga como principios la defensa de los derechos que tiene cada persona por el solo hecho de serlo. Con este objetivo, el padre De las Casas pone en práctica y argumenta teóricamente los principios que se presentan a continuación.

\section{El hombre es libre por naturaleza}

El derecho de los indios a su libertad es el primer punto desde donde parte toda dialéctica humanista lascasiana. Se convierte en uno de los ejes en torno a los cuales gira obsesivamente su pensamiento. Bartolomé sustenta este principio, del que se derivan otros derechos: "desde el principio del género humano y por derecho natural y de gentes, todos los hombres, todas las tierras y todas las otras cosas fueron libres y alodiales, es decir, francas y no sujetas a servidumbre” (De las Casas, 1974a, p. 51). Dentro de este mismo contexto, De las Casas (1969) dice en De regia potestae:

De donde resulta evidente que, no estando demostrado la existencia de alguna esclavitud, en caso de duda nuestro juicio debe ser favorable a la libertad y según su libertad. En consecuencia, se presume que el hombre es libre, mientras no se demuestre lo contrario. (p. 18)

En estos argumentos, a los que hace referencia Galmez (1989), se nota la gran influencia de los estímulos iusnaturalistas racionalistas de Tomás de Aquino, en los que Bartolomé de las Casas encontró el aliento de sus doctrinas, y a partir de los cuales formuló los alegatos en favor del derecho natural a la libertad como facultad 
inherente al ser humano. La sustentación a esta afirmación se encuentra en la siguiente afirmación De las Casas (1974b): "la naturaleza racional no está ordenada a otro ser como a su fin, como de hombre a hombre. Es tesis de Santo Tomás. La libertad es un derecho inherente al hombre necesariamente y desde el principio de la naturaleza racional. Por es de derecho natural” (p. 61).

El derecho a la libertad es, por tanto, una virtud esencialmente suministrada por la naturaleza y no una característica del hombre adquirida por un accidente, que es, según lo interpretado, una situación demandada por la forma de actuar del ser humano, motivado por un cierto tipo de interés particular. Por ello, y según el principio de que la libertad tiene sus cimientos en el derecho natural, todo tipo de sujeción del hombre por el hombre pierde su legitimidad porque no está de suyo sustentado $\mathrm{u}$ originado en causas naturales, sino porque está dispuesto y construido a partir de la norma positiva impuesta por el Estado. Por eso dice De las Casas con relación a la esclavitud de los indios de las Américas:

Todos los indios que se han hechos esclavos en las Indias del mar Océano, desde que se descubrieron hasta hoy, han sido injustamente hechos esclavos, y los españoles poseen a los que hoy son vivos, por la mayor parte, con mala consciencia, aunque sean de los que hobieron de los indios. (De las Casas, 1965, p. 505)

Así, desde este punto de vista, el hombre libre es interpretado como aquel que es dueño de sí mismo, dotado de la facultad y la capacidad de disponer libremente de su persona y cosas conforme a su voluntad, sin prohibición alguna, sea temporal o perpetua, que sería contrario a libertad. Sustentado en este principio, y refiriéndose al caso particular de la situación vivida por los indios de América, el padre De las Casas “opta por la libertad. Pero no ya solo por las libertades cívica y económico-políticas (individuales y comunitarias) de los indios frente a los conquistadores y encomenderos, sino también [...] por una libertad estrictamente pública y soberana [...]” (Abril, 1998, p. 387). Como lo argumenta Polanía (1999), De las Casas encuentra que el único modo de establecer la paz entre los indios y los españoles "es declarando que los indios son tan libres y hombres racionales como lo es cualquier español, que tienen unos derechos que hay que respetar [...]" (p. 46).

Con lo anterior, el padre De las Casas comienza su verdadero aporte a la filosofía política de los derechos humanos y a la estructuración de la actual teoría democrática, porque como principio de libertad se convierte en la base primordial de los siguientes otros principios. 


\section{Los hombres son iguales}

De las Casas encuentra en los indios, al igual que en los demás seres humanos, una sola idea del hombre, una criatura compuesta por un cuerpo físico y por un alma espiritual, características que los dotan de los mismos atributos y, por ende, los mismos derechos y deberes, sin resultar de allí su distinción o discriminación. "No se encuentra ninguna diferencia o especialidad en ningún pueblo con respecto a los demás... [Porque] Cristo nuestro señor [...] no distinguió pueblos de pueblos ni estableció diferencias o especialidad de tiempos ni de lugares” (De las Casas, 1975, p. 337). De aquí resulta, entonces, el principio de igualdad de todos los hombres, concepto de vital trascendencia en la consecución de un mejor trato y una mejor legislación entre las sociedades, ya que, y como lo dicen Redondo y Martin (1992) comentando a De las Casas: "todos son esencialmente iguales y dignos de respeto, y tienen unos derechos, que, por nacer de la naturaleza, son derechos naturales, inviolables e inalienables; y unos atributos fundamentales: racionalidad, libertad y sociabilidad” (p. 65).

Esto muestra que la mente De las Casas se abre a todos los hombres, lo que resalta el principio de la igualdad entre ellos. El padre De las Casas hace su defensa de los indios, y permite que en el futuro este sea uno de los conceptos que tanta trascendencia tenga en la vida de los hombres y en la elaboración de la ley que los dirige.

\section{El hombre goza de la propiedad privada}

Con este principio De las Casas hace importantes críticas a la actitud de algunos conquistadores y españoles de despojar a los indios de su propiedad y de los bienes que poseían, mediante la figura de las “encomiendas”. Él sustentó que el hombre tiene derecho a la propiedad privada y a la convivencia pacífica; así no se le pueden arrebatar sus bienes ni se le puede molestar.

Todo hombre tiene derecho a la paz y convivencia pacífica entre todos los ciudadanos y a ser titular de propiedad privada (y advierte que) ninguna persona sin legitima causa y por razón de interés público, puede ser privada de sus bienes. (De las Casas, 1975, p. 16)

En relación con esto, y utilizando un tono fuerte y decidido, De las Casas argumenta ante el emperador Carlos $\mathrm{V}$ esta notable e importante afirmación:

A ninguna persona de este mundo, ni aun al Rey de los españoles [...], le es lícito, sin la licencia y libre y graciosa voluntad del Rey Inca o de sus descendientes, a quienes, de derecho, según sus leyes o costumbres, pertenezca suceder en sus bienes, 
buscas, escrutar, desenterrar y llevarse con intención de apoderarse de ello, los tesoros, riquezas u objetos preciosos que estos sepultaron en los sepulcros y en los así llamados guacas. (De las Casas, 1958, p. 55)

De esta manera, queda claro que los bienes particulares son de cada uno de los ciudadanos que los poseen, y esta condición les concede poder de soberanía sobre sus pertenencias. Este es un terreno franco y libre sobre el cual no tiene sino dominio el propietario, y por ende tiene derecho a disponer libre y soberanamente de lo que en este se encuentre.

Los reyes y los emperadores no tienen poder fundado sobre las haciendas de los ciudadanos ni tampoco sobre las fincas de los particulares, provincias o tierras del reino ni respecto al dominio útil ni respecto al directo. Por tanto, los dueños de tales cosas no pueden decirse que son por ello vasallos de los reyes o señores. (De las Casas, 1974b, p. 66)

\section{El hombre tiene libre albedrío y libertad religiosa}

Con firmeza y decisión, De las Casas también luchó en contra de cualquier clase de coacción, tortura o violencia hacia los nativos, justificada en su actitud o particular forma de comportarse, o en procura de cambiarle su manera de actuar sin consultar con su voluntad.

Porque para recibir nuestra sancta fe requiere en los que han de aceptar y recibir, prompta libertad de voluntad, porque la dejó Dios en la mano y albedrío de cada uno si quiere o no recibirla [...] sea y este fundado en el querer voluntario de aquellas gentes, y no en fuerza y violencia alguna que se les haga, sin dubda ninguna, muy alto señor, todo lo demás no ha de ser [...] contra su voluntad, sino según y conforme a ella, y aprobándolo y consintiéndolo ellos. (De las Casas, 1985, p. 401)

Así mismo, y refiriéndose ahora a lo que representa un pilar fundamental de la reivindicación histórica de la tolerancia y la libertad religiosa, De las Casas defiende una intervención pacífica para la predicación del evangelio.

Que la providencia divina estableció para todo el mundo y para todos los tiempos un solo, mismo y único modo de enseñarles a los hombres la verdadera religión, a saber; la persuasión del entendimiento por medio de razones y la invitación y suave mención de la voluntad. (De las Casas, 1975, p. 65) 
Esta tesis se podría interpretar como una gran capacidad de tolerancia, respeto y sensibilidad frente a otras formas de creencias religiosas y culturales practicadas por indígenas. A su vez demuestra o procura defender la libertad de conciencia y reconocer la identidad del otro como ser diferente y particular, en este caso la particularidad de los indios.

\section{El hombre tiene dominio sobre sus bienes}

Buscando que los líderes y caciques indígenas conservaran pleno poder y soberanía sobre los bienes que poseían, De las Casas también elaboró algunas teorías en torno a la defensa del derecho público que tenían los caciques en sus tribus. Con ello le quitó validez a la actitud de España de imponer en América gobernantes y dirigentes distintos a los de estirpe indígena.

Luego verdad es competer a los infieles en sus reinos y provincias tener y ser reyes y reinos, y mando y jurisdicciones sobre súbditos, de derecho y ley natural, que se llamen reyes o rectores, caciques o tatoanes u otro cualquier nombre que tengan; e tiene todo cuanto poder los reyes acá entre nosotros los cristianos platicamos o leemos en las leyes y costumbres tener los reyes. (De las Casas, 1974c, p. 1069)

Con este memorial llama la atención frente a aquellos que eran los propietarios legítimos de los bienes de América. Estos eran de propiedad común para todos los que vivían allí. No eran propiedad de los extranjeros que con fuerza y violencia quisieron despojar a los nativos de sus pertenencias. Con esto, el pensamiento de Bartolomé va más allá de los límites propuestos por la época, llegando así a las últimas consecuencias con sus teorías, hasta tal punto que en una carta dirigida a Bartolomé de Carranza y a los reyes de Castilla manifiesta lo siguiente:

Creo yo, como creo en Dios, ser de precepto divino, a ponerla por guerra a mano armada, sino pudieren por paz, con riesgo y peligro de todo lo temporal que tienen en los indios obligados, es sacar los indios del poderío del diablo y ponerlos en su prisma libertad y a sus reyes y señores naturales restituirles sus estados. (De Mendoza, 1867, p. 303)

Esta postura del padre De las Casas demuestra que sus argumentos estaban amparados por importantes razones y por una seguridad personal que rayaba con lo carismático, que sin lugar a dudas ha dejado una valiosa contribución histórica a la 
afirmación de autonomía, libertad e igualdad de las personas, y a la autodeterminación y soberanía de los pueblos y las naciones del mundo.

\section{El pacto constitucional entre pueblo y soberano}

Dentro del contexto del principio relativo al derecho público, el pacto constitucional entre pueblo y soberano estaba dado, según De las Casas, en función de considerar la libertad política como el valor más preciado e inestable que un pueblo libre puede poseer, porque según él:

Originalmente todas las cosas y todos los pueblos fueron libres [de donde si depende que] en el caso de que se impusiera cualquier tipo de carga u obligación contra la voluntad del pueblo o del dueño privado se privaría al pueblo del uso de la libertad que le corresponde por derecho natural. (De las Casas, 1974b, pp. 71-72)

Y sigue diciendo De las Casas (1969) más adelante: “Todos los pueblos son libres y pueden escoger libremente el régimen político que quieran. El poder de la soberanía proviene inmediatamente del pueblo. En la voluntad popular radica la legitimidad de un régimen" (p. 71).

De este modo, los reyes de España, por voluntad propia, no tienen derecho ni pueden disponer de propiedades o bienes de dominio particular del pueblo, ni tampoco son príncipes absolutos o inamovibles de los ciudadanos o del reino, dado que las limitaciones a su libertad individual parten de la legitimidad política emanada del pueblo, la cual se logra a través del pacto democrático que consiga este con el soberano.

El pueblo es la causa eficiente del poder de los reyes. Los derechos de los gobernantes radican en la voluntad soberana de la comunidad política. Al elegir los gobernantes el pueblo no renuncia a su libertad, porque los ciudadanos no obedecen ni se sujetan a un hombre sino a las leyes libremente consentidas y en cuanto se ordenan al bien común. (Pereña, 1981, p. 103) ${ }^{7}$

7 Fragmento de la primera carta americana de los derechos humanos. En este mismo artículo, y refiriéndose a este tema, Pereña (1981) dice: "Los tres principios son: 1. El poder político es el servicio para defender y promover los derechos del ciudadano. 2. El poder político tiene un origen esencialmente democrático. El pueblo es la causa eficiente del poder de los reyes. 3. El gobernante no es más que un administrador que ejerce su autoridad para bien del pueblo" (p. 103). 
Esta es la razón por la cual todo gobierno, para ser considerado como poseedor de un poder político, debe fundamentarse en el pacto o en el consentimiento popular. Así es como las ideas de Bartolomé de las Casas han aportado suficientes elementos teóricos al proceso de la maduración democrática de la humanidad, por cuanto son consideradas como unas de las teorías más revolucionarias de la democracia moderna. El siguiente aparte se centrará en los aportes realizados a la situación política del mundo actual.

\section{Aportes lascasianos más importantes a la democracia y a la política}

La cuestión del Estado y la democracia está reconocida como la problemática teórica y real de mayor trascendencia en el contexto político actual, en la vida cotidiana y en las reflexiones académicas. Además, para la historia se ha constituido como un tema importante y de preocupación, pues a través de ella se ha buscado un sistema político que mediante el acuerdo y el consenso de personas libres, iguales y dotadas de una característica racional busquen para sí el bien común. En otras palabras, la historia ha sido el escenario donde se han librado las luchas y las batallas más intensas que dan origen a algunos mecanismos que posibilitan la conformación de un poder político legítimo logrado con el respaldo de un gran consenso de múltiples y variadas personas, es decir, una comunidad de ciudadanos que tienen como objetivo un bien común. Esta es la manera política y democrática más eficaz para mantener y permitir un orden constitucional justo. Es esta utopía política y democrática la que ha ocupado el pensamiento político de muchos hombres; una constitución democrática en la que los individuos colectivamente pongan sus intereses y busquen juntos, de manera justa y equitativa, la satisfacción de las necesidades de los ciudadanos, lo que sería lograr la justicia mediante la construcción de un Estado democrático.

A esta noción de Estado democrático contribuyó Bartolomé de las Casas al sustentar que el poder del gobernante se cifraba en el pueblo, el cual, al buscar su bien común, tiene la necesidad de nombrar una autoridad que lo gobierne, eso sí, sin perjuicio del bien común. En consecuencia, dice De las Casas (1974a):

[...] conviene a saber, para probar que aquestas indianas gentes tenían pueblos

y ayuntamientos grandes ordenados y edificios en ellos que llamaban ciudades 
donde vivían socialmente, para dello argüir que para constituirse y allegarse a las tales sociedades en compañía que son naturales a los hombres, las cuales se presuponen a seis partes para poder vivir en paz y en ellas conservarse, tuvieron razón y buen juicio y prudencia. (p. 20)

Galmez (1989), además, comenta que en una verdadera intuición de futuro, De las Casas llegó a proponer la solución al asociacionismo político. Para ello, retomó el siguiente argumento del fraile dominico: "Los hombres naturalmente pueden asociarse en colectividades con el fin de vivir políticamente" (De las Casas, citado por Galmez, 1989, p. 19).

Bartolomé de las Casas, al resaltar la importancia de la democracia en la construcción original del Estado, connota, además, la importancia del derecho positivo como fundado de este al ser el medio por el cual se hace visible y se sanciona el derecho natural. En este sentido, el primer carácter del ser humano que debe resaltar el derecho civil es el de su libertad originaria. En un comentario de Beuchot (1994) sobre De las Casas, aparece: "El hombre por naturaleza o esencia es libre y por consiguiente la libertad es un derecho inherente al hombre necesariamente y desde el principio de la naturaleza racional, es por eso que la libertad es de derecho natural" (p. 47). De ahí que, y según este principio, todas las cosas que les son inferiores a los hombres les pertenecen por naturaleza, y como desde el principio estas cosas carecen de dueño y nacen baldías, los seres humanos poseen el derecho de ocuparlas. Quien las ocupa y utiliza en primera instancia por naturaleza se vuelve dueño de estas sin perjuicio a que les sean arrebatadas por extranjeros o extraños. Allí, entonces, estos primeros dueños conforman sus países o naciones, que no pueden ser Estados hasta cuando organicen el poder político.

Este será el modo de establecer una autoridad y un gobierno que les servirá para dirigir armónica y justamente el destino de la comunidad de hombres que la conforman, y que tendrán como última finalidad la perfección humana. Por eso, una comunidad de hombres debe tener como derecho natural o fundamental poseer o estar regidos por una autoridad que no tendrá en sí misma el poder ni su esencia, sino que residirá en el pueblo que lo elige, y este tendrá la potestad de quitar o arrebatar la autoridad al gobernante si este se opone al bien común que por voluntad popular ha elegido el pueblo, según los parámetros de equidad, igualdad y libertad.

Nace, así, la democracia como derecho que tiene el hombre por naturaleza, y que hasta ahora se ha constituido en el mecanismo y en la teoría que se ha proclamado y defendido como la forma más justa y equitativa para conformar y dar autoridad al gobernante. Este debe ejercer y dirigir su territorio con base en los mandatos y 
la voluntad del pueblo, que es en sí mismo el origen y la meta de toda la estructura jurídica y legislativa de un Estado o nación.

El pueblo tiene, por ende, el poder jurisdiccional, y lo da al gobernante, para que procure el bien común. De ahí que puede determinar el derecho, de lo cual resulta lo justo, pero siempre de acuerdo al bien común, que corresponde a la naturaleza humana. Y así, vuelve a basarse el derecho positivo en el derecho natural. Al nivel del derecho de gentes — que es el mismo derecho positivo sancionando al derecho natural - se da un pacto entre súbditos y gobernantes. Se trata de un pacto constitucional por el que el pueblo no pierde su libertad y que ésta es uno de los principales derechos humanos. (Beuchot, 1994, p. 49) ${ }^{8}$

Sobre los aportes De las Casas a la democracia y la política también se pronunció Hanke (1949): “En relación el origen del gobierno, las Casas creía que todos los hombres eran originalmente libres, ya que la libertad individual es un derecho concedido por Dios como atributo esencial del hombre” (p. 45).

Con lo anterior, el padre De las Casas constituye y elabora directrices políticas para mejorar la situación de los indios en el siglo xvi. Sin embargo, y sin pensarlo, hoy, en pleno siglo xxI, son argumentos que pueden mejorar la convivencia humana al suministrar las bases fundamentales para construir Estados y naciones más equilibrados y justos, gracias a sus teorías sobre la justicia y los derechos del hombre. "Bartolomé de las Casas se ha convertido en uno de los teorizantes más revolucionarios de la democracia moderna. Su libro De regia potestae es posiblemente el estado más sensacional 'de su época sobre la democracia y los derechos humanos” (Pérez-Luño, 1998, p. 553).

\section{Contribuciones de Bartolomé de las Casas a la idea de Estado de derecho}

Este aporte de Bartolomé de las Casas a la sociedad moderna parte siempre de creer que la justicia se presenta y se manifiesta en un cuerpo legal o de derecho público. De esta forma, hace que la ley natural ilumine la ley positiva, porque al ser el pueblo el que

8 "Como se ha dicho, el bien común es el fin de la sociedad, y su gobernante debe buscarlo por la justicia, que es el medio por el cual la ley positiva participa de la ley natural [y sigue argumentando Beuchot ahora con palabras libres] está obligado a ordenar su régimen al fin de la multitud (es decir, el bien común), y a gobernarla en cuanto a ella misma” (Beuchot, 1994, p. 50). 
construye tales leyes a través del consenso popular, serán siempre leyes que busquen el bien común para todos, sin distinción. Esta ilusión debe ser administrada por una autoridad o gobernante, que tiene la obligación de cumplir las leyes constituidas por el pueblo por designio natural. Con esto, el pueblo hace eco de su derecho a elegir democráticamente su destino. Así, con la justicia puede incentivar las relaciones equitativas e igualitarias entre los hombres, para lo cual debe siempre tratar de limitar el poder de los gobernantes, quienes buscan solo ser elegidos para lograr el bien individual. Así pues, "la ley encauza la acción de los hombres al bien común y evita el mal contrario a él. Las leyes obligan a todo individuo, incluso al gobernante” (Beuchot, 1994, p. 51).

En palabras de Beuchot, lo que pretendía De las Casas al proteger al pueblo con un sistema de leyes de las actuaciones indiscriminadas de los gobernantes era construir en su época lo que hoy se ha denominado el Estado de derecho. En este modelo de Estado el referéndum se convierte en la herramienta más importante para que el pueblo manifieste su voluntad con respecto al derecho o la aceptación de una ley. Es un mecanismo que le servirá para conservar la libertad como forma indispensable para perfeccionar la sociedad políticamente, porque en la medida en que el hombre mantenga su libertad podrá también mantener y salvaguardar algunos derechos que de ella se desprenden, como el derecho a que cada hombre pueda tener las ideas o la religión que voluntariamente desee. Este derecho nace de la libertad espiritual o de pensamiento, por lo que en ninguna circunstancia o por ningún motivo el ser humano debe ser obligado a aceptar o practicar una religión determinada. Si no se respeta este derecho, el ser humano sería perjudicado en su libertad o en sus bienes, por no practicar una religión establecida. De igual modo, y emanada de la libertad natural, está el derecho del hombre a gozar y a tener libre e individualmente propiedad privada, derecho que se hace extensivo a las naciones.

De lo anterior, puede afirmarse que para De las Casas las leyes, como las demás instituciones, tienen el valor de instrumento o medio para la realización del bien general en la promoción social de todos sus ciudadanos. Además, su tarea es controlar y poner límite a las acciones tiranas y dictatoriales de los gobernantes que por causas particulares quieran atentar contra el bien común pactado por el pueblo.

\section{Conclusiones}

Al recopilar estas tesis sobre la importancia y la contribución de las teorías y reflexiones de Bartolomé de las Casas a la formación histórica de los Estados democráticos y a los 
derechos humanos, es conveniente tener en cuenta que los pensamientos desarrollados frente a las libertades y a los derechos siguen teniendo plena vigencia y actualidad para el sistema tanto social como jurídico de la sociedad moderna, "lo que convierte a Bartolomé de las Casas en un clásico de los derechos humanos” (Pereña, 1981, p. 12).

Dadas, por tanto, estas afirmaciones, se puede aducir que el proceso de formación histórica de los derechos del hombre tuvo en Bartolomé de las Casas y en sus doctrinas un eslabón esencial. Con la influencia que él tuvo de las teorías iusnaturalistas propuestas por los Clásicos Españoles y por la concepción de hombre, muy diferentes de los que hasta su época conocían, que le planteó la relación con las nuevas culturas de los pueblos primitivos del Nuevo Mundo, diseñó y elaboró, en un corto tiempo, premisas y argumentos jurídico-políticos que sirvieran para impedir el trato inhumano hacia muchos aborígenes por parte de los conquistadores españoles.

Con lo anterior, se le deben reconocer a Bartolomé de las Casas los esfuerzos por plantear en su época unos derechos básicos que le sirvieron para defender las libertades de los indígenas, y que hoy en día permiten sentar las bases para buscar entre los hombres relaciones de mayor convivencia y armonía al considerar el derecho natural. De igual modo, las reflexiones lascasianas han permitido y ayudado a través de la historia a conformar intelectual e institucionalmente todo el proceso de construcción de los derechos, en especial de aquellos que se enmarcan desde la época medieval hasta los modernos derechos humanos.

Los aportes más importantes del padre De las Casas a la actual teoría de los derechos humanos están dados en los puntos que se esbozan a continuación. El primero de ellos es la concepción y la teoría que se desarrollan con relación a las libertades. Esta se inspira esencialmente en las consideraciones humanistas e iusnaturalistas predominantes en la Edad Media. Tal influencia fue suministrada al defensor de los indios en dos sentidos o puntos de vista contrapuestos. Uno de estos se funda en la idea de la libertad ejercida según el principio de la autoridad y el poder teológico-político del siglo XVI, que se basaba en una concepción voluntarista de la libertad heredada del Medioevo. La segunda concepción de la libertad está dada y suministrada por los estímulos del iusnaturalismo racionalista de Tomás de Aquino, que en principio fueron tomados por Francisco de Vitoria y luego por De las Casas para, desde allí, fundamentar los argumentos más significativos sobre las libertades. 
El segundo de los aportes más sobresalientes de De las Casas a la teoría política de nuestro tiempo está en aquellas teorías que, relacionadas con la libertad política o con el pacto social, se construyeron con una gran visión de futuro, pues hoy en día se consideran un anticipo notable a los derroteros democráticos de la moderna filosofía jurídico-política.

Finalmente, De las Casas hizo su mayor aporte a la época moderna con los argumentos estructurados sobre los derechos humanos. Su teoría suscita interés en la actualidad porque sus conceptos siguen siendo un elemento importante para aumentar los principios de libertad, igualdad y dignidad humana.

\section{Sobre el autor}

José Wilmar Pino Montoya. Filósofo y politólogo de la Universidad de Antioquia. Sus estudios de posgrado los realizó en universidades de Colombia; es magíster en Educación de la Universidad de Manizales y el Centro Internacional de Educación y Desarrollo, y doctor en Filosofía de la Universidad Pontificia Bolivariana, sede Medellín. Actualmente es docente investigador de la Facultad de Educación y Humanidades de la Universidad Católica Luis Amigó, Medellín. Sobre sus intereses investigativos dan cuenta varias publicaciones desarrolladas en el periodo 2018-2019.

\section{Referencias}

Abril, C. (1998). Bartolomé de las Casas y la Escuela de Salamanca en la historia de los derechos humanos. Studium, 3(3), 373-402.

Aristóteles. (1994). La política. Madrid: Gredos.

Aristóteles. (1999). Acerca del alma. Madrid: Gredos.

Beuchot, M. (1986). La actualidad de la antropología filosófica de Fray Bartolomé de las Casas. Cuadernos de Realidades Sociales, (27-28), 255-265.

Beuchot, M. (1991). Bartolomé de las Casas: la filosofía al servicio de la defensa de los derechos humanos de los indios. Cuadernos Venezolanos de Filosofía, (5-6), 73-79.

Beuchot, M. (1994). Los fundamentos de los derechos humanos en Fray Bartolomé de las Casas. España: Anthropos.

Carrión, R. (1991). Tópicos del pensamiento colonial: filosofía escolástica, iusnaturalismo y derecho moderno. Cuadernos Venezolanos de Filosofía, (3), 97-105.

De Dios de Dios, S. (2006). Corrientes jurisprudenciales, siglos XVI-XVII. En L. E. San Pedro Bezales Rodríguez (Coord.), Historia de la Universidad de Salamanca. Vol. 3, t. 1: Saberesy confluencias (pp. 75-102). España: Universidad de Salamanca. 
De las Casas, B. (1941). Doctrina. México: Ediciones de la Universidad Nacional Autónoma de México.

De las Casas, B. (1958). Los tesoros del Perú. Madrid: Aldeco.

De las Casas, B. (1962). Tratado de Indias y el doctor Sepúlveda. Venezuela: Academia Nacional de la Historia.

De las Casas, B. (1965). Tratados. T. 1. México: Fondo de Cultura Económica.

De las Casas, B. (1969). De regia potestate. Madrid: Consejo Superior de Investigaciones Científicas.

De las Casas, B. (1974a). Los indios de México y Nueva España. Antología. 3. ${ }^{\text {a }}$ ed. México: Porrúa.

De las Casas, B. (1974b). Derechos civiles y políticos. Madrid: Editorial Nacional San Agustín.

De las Casas, B. (1974c). Tratados. T. 2. México: Fondo de Cultura Económica.

De las Casas, B. (1975). Del único modo de atraer a todos los pueblos a la verdadera religión. México: Fondo de Cultura Económica.

De las Casas, B. (1985[1552]). Obra indigenista. Madrid: Alianza Editorial.

De la Puente, J. (1999). La declaración universal de los Derechos Humanos: una visión desde la historia. En F. Novak y J.J. Ruda (Coords.), Cincuenta años de la Declaración de los Derechos Humanos (13-30). San Miguel: Fondo Editorial de la Universidad Católica del Perú.

De Mendoza, L. (1867). Documentos inéditos, relativos al descubrimiento, conquista y organización de las antiguas posesiones españolas de América y Oceanía. T. 7. Madrid: Imprenta de Frías y Compañía.

Fraile, G. y Urdanoz, T. (1985). Historia de la filosofía española I: desde la época romana hasta fines del siglo XVII. Madrid: Biblioteca de Autores Cristianos.

Galmez, L. (1989). Bartolomé de las Casas el hombre y el apóstol. Documentos para el Diálogo, (22), 11-22.

Ginés de Sepúlveda, J. (1996). Tratado sobre las justas causas de la guerra contra los indios. 3. ${ }^{\mathrm{a}}$ ed. México: Fondo de Cultura Económica.

González, M. y Bustamante, F. (1997). Qué son los derechos humanos y como han llegado a serlo. Cultura Política y Derechos Humanos, 1, 7-22.

Hanke, L. (1949). Bartolomé de las Casas. Pensador político, historiador, antropólogo. La Habana: UCAR García.

Hanke, L. (1965). Bartolomé de las Casas. Letrado y propagandista. Bogotá: Tercer mundo.

Juan XXIII. (1963). Cartaencíclica:Pacem in terris. Roma:Santa Sede. Recuperadodehttp://www. vatican.va/content/john-xxiii/es/encyclicals/documents/hf_j-xxiii_enc_11041963_pacem.pdf

Matos, J. (1990). A propósito de Fray Bartolomé de las Casas: los nuevos retos del indigenismo al final del milenio. México: Universidad Nacional Autónoma de México. 
Novak, F. y Ruda, J. (1999). Cincuenta años de la Declaración de los Derechos Humanos. San Miguel: Fondo Editorial de la Universidad Católica del Perú.

Papacchini, A. (1995). Filosofía y derechos humanos, ciudad y democracia. Santiago de Cali: Universidad del Valle.

Pereña, L. (1981). Fray Bartolomé de las Casas: profeta de la liberación. Universitas Humanística, 10(14), 93-108.

Pérez-Luño, A. (1998). Los clásicos iusnaturalistas españoles. En F. J. Ansuátegui Roig, J. M. Rodríguez Uribes, G. Peces-Barba Martínez y E. Fernández García (Coords.), Historia de los derechos fundamentales. Vol. 1 (505-570). Madrid: Dikynson-Instituto de Derechos Humanos Bartolomé de las Casas-Universidad Carlos de Madrid.

Pino, J. (2003). Fray Bartolomé de las Casas y su visión filosófica antropológica de los derechos del hombre (tesis de grado). Universidad de Antioquia, Medellín, Colombia.

Polanía, T. (1999). Fray Bartolomé de las Casas y los Derechos Humanos. Principia Iuris, 2(2), 41-48.

Redondo, J. y Martin, A. (1992). Bartolomé de las Casas, el defensor de los indios. Barcelona: Planeta.

Salazar, C. A. (2000). Dayi Drua, nuestra tierra: comunidad y territorio indígena de Antioquia. Medellín: Gobernación de Antioquia.

Santamaria, C. A. (1982). Fray Bartolomé de las Casas y las Leyes de Indias. Correo de los Andes, (16), 49-54.

Universidad Autónoma Latinoamericana y Corporación de Promoción Popular. (2001). Módulo de enfoques: Diplomado Justicia, conflicto y Derechos Humanos. Medellín: Escuela de Justicia Comunitaria.

Vitoria, F. (1974). Relecciones del Estado, de los indios y del derecho de la guerra. México: Porrúa. 